\title{
Survival of patients with kidney cancer in central and northern Denmark, 1998-2009
}

This article was published in the following Dove Press journal:

Clinical Epidemiology

19 July 2011

Number of times this article has been viewed

\author{
Tau Pelant ${ }^{1,2}$ \\ Erik Højkjær Larsen ${ }^{1,2}$ \\ Lars Lund ${ }^{3}$ \\ Michael Borre ${ }^{4}$ \\ Rune Erichsen' \\ Mette Nørgaard' \\ Jacob Bonde Jacobsen' \\ 'Department of Clinical Epidemiology, \\ Aarhus University Hospital, \\ Denmark; ${ }^{2}$ Department of Urology, \\ Aarhus University Hospital, \\ Aalborg, Denmark; ${ }^{3}$ Department of \\ Urology, Viborg Hospital, Denmark; \\ ${ }^{4}$ Department of Urology, Aarhus \\ University Hospital, Skejby, Denmark
}

Correspondence: Erik Højkjær Larsen Department of Urology, Aarhus University Hospital, Aalborg, Reberbansgade 15, Aalborg 9000, Denmark

Tel +459932 |498

Email ehl@rn.dk
Objective: For decades, kidney cancer patients in Denmark have had lower survival than patients in the other Scandinavian countries. Our aim was to study possible changes in survival of patients with kidney cancer after implementation of two national Danish cancer plans.

Study design and setting: From 1998 through 2009 we included all patients $(\mathrm{N}=2659)$ with an incident diagnosis of kidney cancer in two Danish regions (population 1.8 million). Data were retrieved from the Danish National Registry of Patients. We computed survival after 1, 3, and 5 years, stratified by age, and estimated mortality rate ratios (MRRs) using Cox regression to assess changes over time, controlling for age and gender. We lacked data on stage distribution. Among patients who had a nephrectomy we also computed 30-day mortality and 30-day MRRs.

Results: During the study period, we identified 2659 patients with kidney cancer. The annual number of patients increased from 583 in the period 1998-2000 to 853 in the period 2007-2009. The median age at diagnosis was 69 years throughout the study period. The overall 1-year survival improved from 56\% (1998-2000) to 63\% (2007-2009), corresponding to an adjusted MRR of 0.78 (95\% confidence interval [CI] 0.66-0.93). We predicted the 3-year survival to increase from $40 \%$ to $51 \%$ and the 5 -year survival to increase from $33 \%$ to $42 \%$, corresponding to predicted MRRs of 0.76 (95\% CI 0.66-0.87) and 0.77 (95\% CI 0.68-0.89), respectively. Survival increased in all age groups (15-59 years, 60-74 years, $75+$ years) and in both genders, except for men below 60 years, for whom the 1 -year survival declined from $76 \%$ to $69 \%$. The 30 -day mortality after nephrectomy declined from $4 \%$ to $2 \%$ during the study period.

Conclusion: We observed an improvement in the survival and relative mortality in kidney cancer patients, although not in men younger than 60 years.

Keywords: kidney neoplasm, outcome research, mortality rate ratio, MRR

\section{Introduction}

Kidney cancer is the third most common genitourinary cancer. ${ }^{1-3}$ In Europe, the standardized incidence (to the World Health Organization world standard population) is 8.8 per 100,000 , with a standardized incidence of 5.1 per 100,000 in women and 10.5 per 100,000 in men. ${ }^{3}$ In Denmark, the number of new cases reported in 2009 was 669; of these, 420 cases were seen in men and 249 in women. ${ }^{2}$

A study on survival of patients with kidney cancer in the Nordic countries in the period 1964-2003 found that throughout the study period kidney cancer patients in Denmark had the lowest 5-year relative survival ratios for both men and women compared with the other Scandinavian countries. ${ }^{4}$ For patients diagnosed between 1999 and 2003, the relative survival was 40\% (95\% confidence interval [CI] 38-43) 
for Danish women and 41\% (95\% CI 38-43) for Danish men, while survival in the other Nordic countries ranged between $52 \%$ and $62 \%$ for women and between $51 \%$ and $69 \%$ for men. ${ }^{4}$

In 1998, Engeland et al published a study that compared relative survival of cancer patients between Denmark and the other Nordic countries and found that for cancers of the stomach, colon, rectum, breast (female), and prostate the Danish patients had a markedly lower relative survival than the patients in the other countries. ${ }^{5}$ As a response to such poorer prognosis, the Danish National Board of Health launched the National Cancer Treatment Plans I and II in 2000 and 2005, focusing on improvement of cancer treatment in Denmark. ${ }^{6}$ The Cancer Treatment Plans focused on centralization of treatment, national clinical guidelines, shorter diagnostic delay, and establishment of multidisciplinary cancer teams. Hypothesizing that improvement of treatment of kidney cancer would lead to better survival and lower mortality from kidney cancer in Denmark, we used data from the population-based Danish National Registry of Patients (DNRP) from 1998 to 2009 to examine potential changes in the survival of kidney cancer patients.

\section{Material and methods}

We conducted this study in the central and the northern Denmark regions, with a combined population of 1.8 million. The study period was divided into the following four consecutive time periods: 1998-2000, 2001-2003, 2004-2006, and 2007-2009. The National Health Service provides tax-supported health care for all inhabitants in Denmark, guaranteeing free access to hospitals. Virtually no kidney cancer patients were treated in private hospitals during the study period.

\section{Identification of kidney cancer patients}

Through the DNRP, we identified all patients who had a first-time hospitalization with kidney cancer in the period January 1, 1998 through December 31, 2009. The DNRP contains information about all admissions from nonpsychiatric hospitals in Denmark since 1977. ${ }^{7}$ Outpatient and emergency room visits at hospitals have been included since 1995. This registry includes information on civil registration number, dates of admission and discharge, surgical procedure(s) performed, and up to 20 diagnoses from each hospital contact. Diagnoses have been classified according to the International Classification of Diseases (ICD) 8th edition until the end of 1993 and 10th edition (ICD-10) thereafter. The ICD-10 codes used to identify kidney cancer were DC 64.9 and DC 65.9. We used the DNPR to identify nephrectomy procedures (KAC.00 [nephrectomy], KAC.01 [percutaneous endoscopic nephrectomy], KAC.20 [nephroureterectomy], and KAC.21 [percutaneous endoscopic nephroureterectomy]) conducted within 90 days of kidney cancer diagnosis.

\section{Survival}

Since 1968, the Central Office of Civil Registration has assigned a unique 10-digit personal identification number to all Danish citizens. ${ }^{8}$ This number, unique to each Danish resident, is used in all Danish registries, allowing unambiguous individual-level data linkage. From the Civil Registration System we also obtained information on vital status (dead or alive), date of death, and residence for all cancer patients.
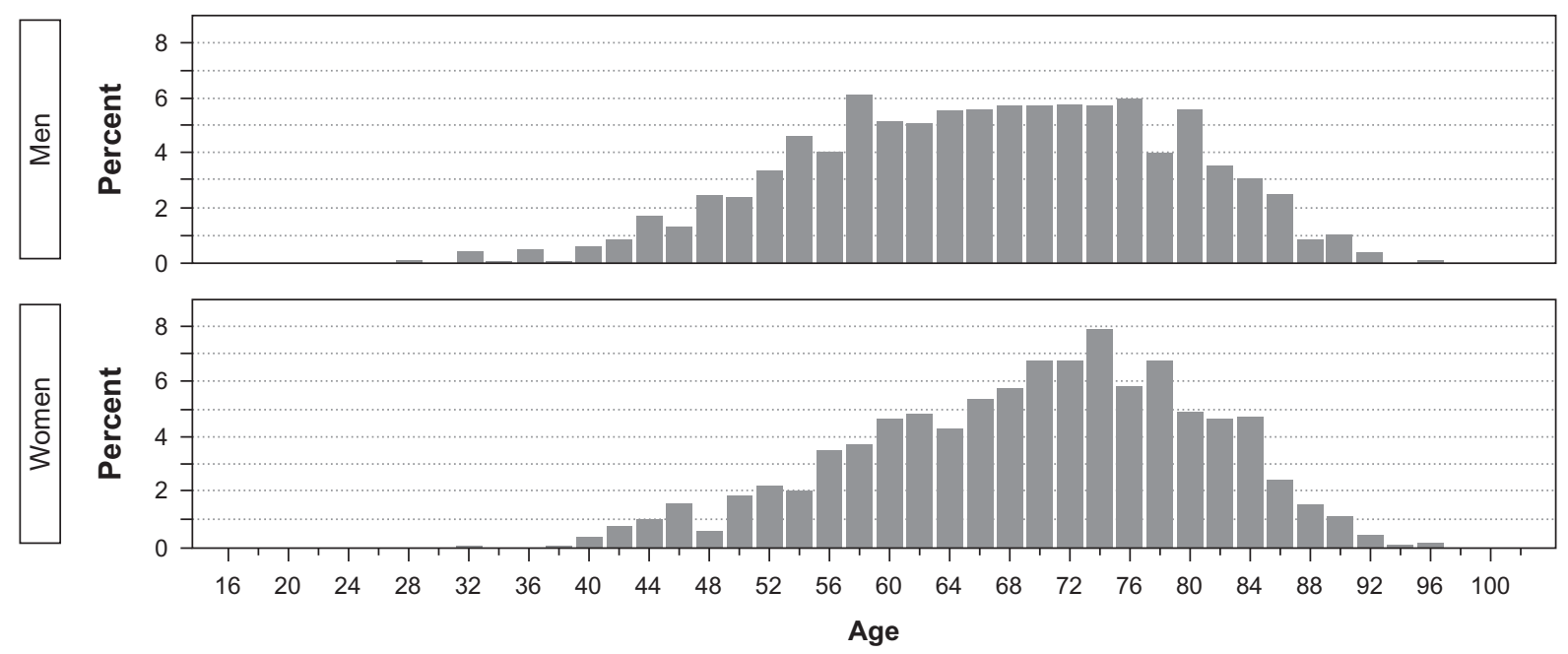

Figure I Age distribution at the time of diagnosis for men and women with kidney cancer in the period 1998-2009 in the central and the northern Denmark regions. 


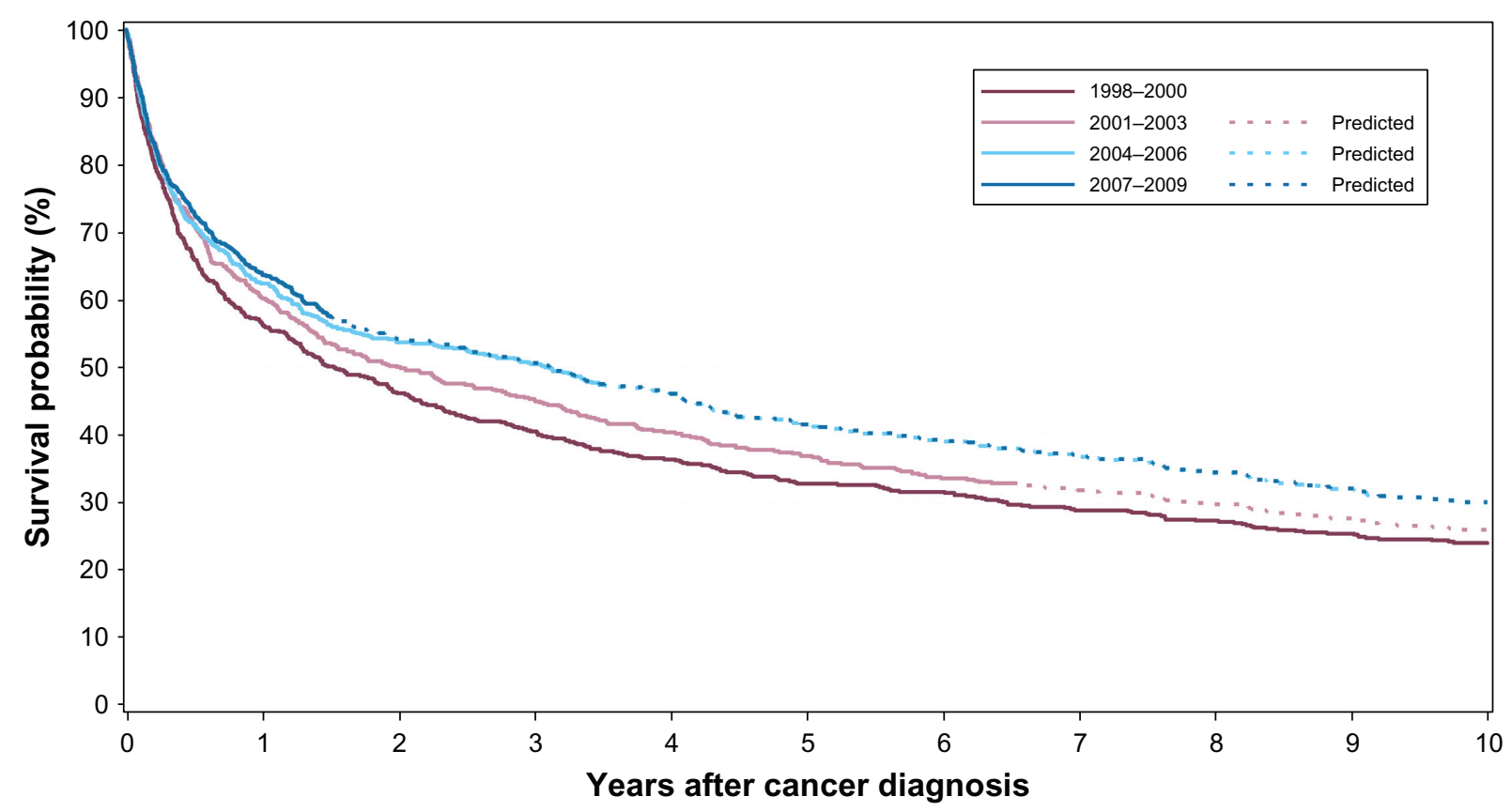

Figure 2 Overall survival of Danish kidney cancer patients diagnosed in the period 1998-2009 in the central and the northern Denmark regions.

\section{Statistical analysis}

We followed each patient from date of cancer diagnosis until emigration, death, or June 25, 2010, whichever came first. To visualize crude survival, we constructed KaplanMeier curves stratified according to period of diagnosis (1998-2000, 2001-2003, 2004-2006, and 2007-2009). We estimated 1-, 3-, and 5-year survival. In the latter periods we estimated 3- and 5-year survival using a hybrid analysis in which we included the actual survival for as long as possible and then estimated the conditional probability of surviving thereafter based on the corresponding survival experience of patients in the previous period (ie, using a period analysis technique). ${ }^{9}$ To compare mortality over time we used Cox proportional hazards regression analysis with $1998-2000$ as the reference period to estimate 1-, 3-, and 5-year mortality rate ratios (MRRs) and corresponding 95\% CIs adjusting for age group ( $15-59$ years, $60-74$ years, $\geq 75$ years) and gender. In separate models we included age as a continuous variable and as a cubic spline with three knots, respectively.

For the patients who underwent nephrectomy within 90 days of kidney cancer diagnosis, we likewise computed 30-day mortality rates after surgery for the four time periods.

Table I One-, 3-, and 5-year crude cumulative survival and gender- and age-adjusted all-cause MRRs in Danish kidney cancer patients, 1998-2009

\begin{tabular}{|c|c|c|c|c|}
\hline & \multicolumn{4}{|c|}{ Year of diagnosis } \\
\hline & 1998-2000 & $200 I-2003$ & 2004-2006 & 2007-2009 \\
\hline Number of cancer patients & 583 & 571 & 652 & 853 \\
\hline Median age (years) & 69 & 69 & 69 & 68 \\
\hline \multicolumn{5}{|l|}{ I year } \\
\hline Survival & $56 \%(52 \%-60 \%)$ & $60 \%(56 \%-64 \%)$ & $62 \%(59 \%-66 \%)$ & $63 \%(60 \%-67 \%)$ \\
\hline MRR & I (reference) & $0.87(0.73-1.04)$ & $0.82(0.69-0.98)$ & $0.79(0.67-0.94)$ \\
\hline Adjusted $M R^{a}$ & I(reference) & $0.90(0.75-1.07)$ & $0.84(0.70-1.00)$ & $0.78(0.66-0.93)$ \\
\hline \multicolumn{5}{|l|}{3 year } \\
\hline Survival & $40 \%(36 \%-44 \%)$ & $45 \%(41 \%-49 \%)$ & $50 \%(47 \%-54 \%)$ & $51 \%(47 \%-54 \%)^{b}$ \\
\hline MRR & I (reference) & $0.88(0.75-1.02)$ & $0.78(0.67-0.91)$ & $0.77(0.66-0.88)^{\mathrm{b}}$ \\
\hline Adjusted $M^{2} R^{a}$ & I(reference) & $0.90(0.77-1.05)$ & $0.78(0.67-0.91)$ & $0.76(0.66-0.87)^{\mathrm{b}}$ \\
\hline \multicolumn{5}{|l|}{5 year } \\
\hline Survival & $33 \%(29 \%-37 \%)$ & $37 \%(33 \%-41 \%)$ & $41 \%(38 \%-45 \%)^{b}$ & $42 \%(38 \%-45 \%)^{b}$ \\
\hline Relative MRR & $\mathrm{I}($ reference) & $0.89(0.77-1.02)$ & $0.80(0.69-0.92)^{\mathrm{b}}$ & $0.79(0.69-0.90)^{\mathrm{b}}$ \\
\hline Adjusted $M R^{a}$ & I (reference) & $0.91(0.79-1.05)$ & $0.80(0.70-0.92)^{\mathrm{b}}$ & $0.77(0.68-0.89)^{\mathrm{b}}$ \\
\hline
\end{tabular}

Notes: The corresponding $95 \%$ confidence intervals are given in parentheses; adjusted for age and gender; ${ }^{b}$ predicted values. 
We used Cox proportional hazards regression analysis and estimated 30-day MRRs with 1998-2000 as the reference period, adjusting for age group and gender. Analyses were performed using SAS version 9.2 (SAS Institute Inc, Cary, NC).

\section{Results}

A total of 2659 patients was diagnosed with kidney cancer in the period 1998-2009. Of these patients, 1579 were men and 1080 were women. The annual number of patients diagnosed with kidney cancer increased from 583 in 1998-2000 to 853 in 2007-2009. The median age at diagnosis was 69 years in the study period. The age distribution for each gender is shown in Figure 1. Overall, the survival improved over the study period (Figure 2); the 1-year survival improved from $56 \%$ in $1998-2000$ to $63 \%$ in $2007-2009$, corresponding to an age and gender adjusted MRR of 0.78 (95\% CI 0.66-0.93) (Table 1). It is expected that the 3 -year survival will increase from $40 \%$ in $1998-2000$ to $51 \%$ in 2007-2009, and the 5-year survival from $33 \%$ to $42 \%$, corresponding to predicted age and gender adjusted MRRs of 0.76 (95\% CI 0.66-0.87) and 0.77 (95\% CI 0.68-0.89) respectively (Table 1). Including age as either a continuous variable or as a spline in the model did not change these estimates.

Tables 2 and 3 show 1-, 3-, and 5-year survival for each gender, stratified by age. For women, an improvement in survival was observed throughout the study period. For men, an improvement was seen above the age of 60 years, whereas men younger than 60 years seemed not to have experienced the same improved survival.
From 1998 to 2009, the annual number of patients who received a nephrectomy within 90 days of kidney cancer diagnosis increased from 282 patients in 1998-2000 (corresponding to $48.4 \%$ of patients diagnosed in this period) to $411(48.2 \%)$ in 2007-2009. During the study period the 30 -day mortality varied between $3.5 \%$ and $2.2 \%$, corresponding to an age- and gender-adjusted 30-day MRR of 0.62 (95\% CI 0.25-1.52) in 2007-2009 compared with 1998-2000 (Table 4).

\section{Discussion}

In the study population of more than 2500 patients with kidney cancer, we observed an increase in the survival over the study period; although not for men below 60 years of age. At the same time, the annual number of patients diagnosed with kidney cancer also increased.

Our use of data collected through a uniformly organized health care system with free access for all patients allowed for a population-based design with complete follow-up. This minimizes the risk of referral and selection bias. Furthermore, although no validation studies of the coding of kidney cancer in the DNPR exists, a previous study comparing ovarian cancer data from the DNPR with data from the Danish Cancer Registry found a completeness of $96 \%$ and a positive predictive value of $87 \% .{ }^{10}$ We have no reason to believe that the coding quality of kidney cancer is inferior to that of ovarian cancer, and thus, we do not expect misclassification of the kidney cancer diagnosis in the DNPR to have major impact on our estimates.

Table 2 One-, 3-, and 5-year survival and MRRs in Danish men with kidney cancer, 1998-2009, stratified by age group

\begin{tabular}{|c|c|c|c|c|}
\hline \multirow{2}{*}{$\begin{array}{l}\text { Men } \\
\text { Age (years) }\end{array}$} & \multicolumn{4}{|c|}{ Year of diagnosis } \\
\hline & $1998-2000$ & $200 I-2003$ & 2004-2006 & 2007-2009 \\
\hline \multicolumn{5}{|l|}{$15-59$} \\
\hline Number of cancer patients & 99 & 117 & $|3|$ & 148 \\
\hline I-year survival & $76 \%(66 \%-83 \%)$ & $72 \%(63 \%-79 \%)$ & $78 \%(70 \%-84 \%)$ & $69 \%(60 \%-76 \%)$ \\
\hline 3-year survival & $62 \%(51 \%-70 \%)$ & $57 \%(48 \%-66 \%)$ & $66 \%(57 \%-73 \%)$ & $59 \%(50 \%-66 \%)^{\mathrm{a}}$ \\
\hline 5-year survival & $55 \%(44 \%-64 \%)$ & $54 \%(44 \%-62 \%)$ & $60 \%(51 \%-67 \%)^{\mathrm{a}}$ & $53 \%(45 \%-61 \%)^{\mathrm{a}}$ \\
\hline \multicolumn{5}{|l|}{$60-74$} \\
\hline Number of cancer patients & 136 & 137 & 159 & 226 \\
\hline I-year survival & $57 \%(48 \%-64 \%)$ & $66 \%(57 \%-73 \%)$ & $64 \%(56 \%-71 \%)$ & $67 \%(60 \%-73 \%)$ \\
\hline 3-year survival & $45 \%(36 \%-53 \%)$ & $48 \%(39 \%-56 \%)$ & $55 \%(47 \%-63 \%)$ & $54 \%(47 \%-61 \%)^{\mathrm{a}}$ \\
\hline 5-year survival & $35 \%(27 \%-43 \%)$ & $35 \%(27 \%-43 \%)$ & $42 \%(34 \%-50 \%)^{\mathrm{a}}$ & $41 \%(34 \%-48 \%)^{a}$ \\
\hline \multicolumn{5}{|l|}{ 75+ } \\
\hline Number of cancer patients & 100 & 86 & 102 & 138 \\
\hline I-year survival & $43 \%(33 \%-52 \%)$ & $51 \%(40 \%-61 \%)$ & $43 \%(33 \%-52 \%)$ & $47 \%(38 \%-55 \%)$ \\
\hline 3-year survival & $26 \%(18 \%-35 \%)$ & $36 \%(26 \%-46 \%)$ & $31 \%(23 \%-40 \%)$ & $36 \%(28 \%-45 \%)^{\mathrm{a}}$ \\
\hline 5-year survival & $18 \%(11 \%-26 \%)$ & $26 \%(17 \%-35 \%)$ & $22 \%(14 \%-30 \%)^{\mathrm{a}}$ & $24 \%(17 \%-33 \%)^{\mathrm{a}}$ \\
\hline
\end{tabular}

Notes: The corresponding $95 \%$ confidence intervals are given in parentheses; ${ }^{2}$ predicted values.

Abbreviation: MRR, mortality rate ratio. 
Table 3 One-, 3-, and 5-year survival and MRRs in Danish women with kidney cancer, 1998-2009, stratified by age group

\begin{tabular}{|c|c|c|c|c|}
\hline \multirow{2}{*}{$\begin{array}{l}\text { Women } \\
\text { Age (years) }\end{array}$} & \multicolumn{4}{|c|}{ Year of diagnosis } \\
\hline & $1998-2000$ & $200 I-2003$ & 2004-2006 & 2007-2009 \\
\hline \multicolumn{5}{|l|}{$15-59$} \\
\hline Number of cancer patients & 51 & 54 & 52 & 71 \\
\hline I-year survival & $75 \%(60 \%-84 \%)$ & $72 \%(58 \%-82 \%)$ & $65 \%(51 \%-77 \%)$ & $77 \%(65 \%-85 \%)$ \\
\hline 3-year survival & $49 \%(35 \%-62 \%)$ & $63 \%(49 \%-74 \%)$ & $58 \%(43 \%-70 \%)$ & $68 \%(54 \%-78 \%)^{\mathrm{a}}$ \\
\hline 5-year survival & $41 \%(28 \%-54 \%)$ & $54 \%(40 \%-66 \%)$ & $54 \%(40 \%-66 \%)^{a}$ & $63 \%(49 \%-74 \%)^{\mathrm{a}}$ \\
\hline \multicolumn{5}{|l|}{ 60-74 } \\
\hline Number of cancer patients & 116 & 108 & 118 & 146 \\
\hline I-year survival & $59 \%(49 \%-67 \%)$ & $58 \%(48 \%-67 \%)$ & $65 \%(56 \%-73 \%)$ & $74 \%(66 \%-81 \%)$ \\
\hline 3-year survival & $41 \%(32 \%-50 \%)$ & $39 \%(30 \%-48 \%)$ & $52 \%(42 \%-60 \%)$ & $58 \%(49 \%-66 \%)^{\mathrm{a}}$ \\
\hline 5-year survival & $34 \%(26 \%-43 \%)$ & $32 \%(24 \%-41 \%)$ & $44 \%(35 \%-52 \%)^{\mathrm{a}}$ & $49 \%(40 \%-58 \%)^{\mathrm{a}}$ \\
\hline \multicolumn{5}{|l|}{$75+$} \\
\hline Number of cancer patients & 81 & 69 & 90 & 124 \\
\hline I-year survival & $33 \%(23 \%-44 \%)$ & $35 \%(24 \%-46 \%)$ & $53 \%(43 \%-63 \%)$ & $49 \%(40 \%-57 \%)$ \\
\hline 3-year survival & $19 \%(\mid 1 \%-28 \%)$ & $26 \%(16 \%-37 \%)$ & $36 \%(26 \%-45 \%)$ & $33 \%(25 \%-41 \%)^{\mathrm{a}}$ \\
\hline 5-year survival & $12 \%(6 \%-20 \%)$ & $20 \%(12 \%-30 \%)$ & $25 \%(16 \%-34 \%)^{a}$ & $23 \%(16 \%-31 \%)^{a}$ \\
\hline
\end{tabular}

Notes: The corresponding $95 \%$ confidence intervals are given in parentheses; apredicted values.

Abbreviation: MRR, mortality rate ratio.

When interpreting our findings we also need to consider weaknesses of our study. Since we did not include information about the general population in our region we could not compute incidence rates. We therefore could not confirm that the increase in the annual number of kidney cancer cases also reflected an increasing incidence of kidney cancer in northern Denmark. Another weakness was our lack of information on clinical characteristics such as cancer stage at diagnosis and cancer-directed treatment, other than nephrectomy. We were therefore unable to examine whether changes in stage or treatment could explain our findings of an improved survival. A previous study in patients diagnosed with rectal cancer in the Nordic countries and Scotland found that part of the differences in survival could be explained by differences in stage distribution between Denmark and the other countries. ${ }^{11}$ Therefore, a high prevalence of advanced stage at diagnosis could be a possible explanation of the lower survival for Danish kidney cancer patients. Because we lacked stage information, we could not compare the stage distribution with that of kidney cancer patients in other countries. Moreover, we could not examine whether our increasing annual number of kidney cancer patients was a result of increasing use of abdominal imaging giving rise to a higher proportion of early stage cancers and incidentalomas. ${ }^{12-15}$ If so, such tumors could be slow-growing lesions (not yet causing symptoms) with a better prognosis and thereby falsely improving the observed survival in the later study periods as compared with the early study period (length time bias). Another weakness is our lack of information regarding comorbidity and lifestyle factors, and we are therefore unable to examine whether changes in these factors may influence survival over time. A number of other factors may explain the improved survival observed in our study. Following the National Cancer Treatment Plans, a more aggressive diagnostic strategy has been implemented resulting in earlier diagnosis and thus an increased likelihood of curative treatment. If more patients are being diagnosed at an earlier stage in the most recent periods, they will be living longer with the kidney cancer

Table 4 Thirty-day mortality and MRR after nephrectomy in Danish patients with kidney cancer, 1998-2009

\begin{tabular}{lllll}
\hline & Year of surgery & & & \\
\cline { 2 - 5 } & I998-2000 & 200I-2003 & 2004-2006 & 2007-2009 \\
\hline Number of cancer patients & 282 & 309 & 330 & $4 I I$ \\
Median age (years) & 67 & 66 & 64 & 65 \\
30-day mortality & $3.5 \%(I .9 \%-6.5 \%)$ & $2.3 \%(I . I \%-4.7 \%)$ & $2.7 \%(I .4 \%-5.2 \%)$ & $2.2 \%(I .1 \%-4.2 \%)$ \\
30 -day MRR & I (reference) & $0.63(0.24-I .66)$ & $0.77(0.3 I-I .89)$ & $0.6 I(0.25-I .5 I)$ \\
30 -day MRR & I (reference) & $0.66(0.25-I .72)$ & $0.8 I(0.33-I .99)$ & $0.62(0.25-I .52)$ \\
\hline
\end{tabular}

Notes: The corresponding $95 \%$ confidence intervals are given in parentheses; adjusted for age and gender.

Abbreviation: MRR, mortality rate ratio. 
diagnosis even without any improvements in time of death (lead-time bias). Improved surgical technique, extensive use of minimally invasive surgical procedures, and the introduction of new medical treatment modalities such as tyrosine kinase and mTOR (mammalian target of rapamycin) inhibitors also have the potential to improve survival. ${ }^{16-18}$ However, several of these different initiatives have only recently been implemented, and therefore the full effect on overall cancer survival still remains to be seen.

\section{Conclusion}

In this 12-year period in northern Denmark we found an increasing annual number of kidney cancer patients. This increase was followed by a limited improvement in survival and relative mortality, although not in men younger than 60 years.

\section{Financial support}

The study received financial support from the Karen Elise Jensen Foundation, Department of Clinical Epidemiology's Research Foundation, and the Regional Clinical Epidemiological Monitoring Initiative for central and northern Denmark regions.

\section{Disclosure}

The authors report no conflicts of interest in this work.

\section{References}

1. American Cancer Society. Cancer Facts and Figures 2010. Atlanta: American Cancer Society; 2010.

2. The National Board of Health. Cancer incidence in Denmark 2009 [in Danish]. Available from: http://www.sst.dk/publ/Publ2010/DOKU/ Registre/Cancerregisteret2009.pdf. Accessed May 17, 2011.

3. Ferlay J, Shin HR, Bray F, Forman D, Mathers C, Parkin DM. GLOBOCAN 2008, Cancer Incidence and Mortality Worldwide: IARC CancerBase No. 10 [Internet]. Lyon, France: International Agency for Research on Cancer; 2010.
4. Engholm G, Hakulinen T, Gislum M, et al. Trends in the survival of patients diagnosed with kidney or urinary bladder cancer in the Nordic countries 1964-2003 followed up to the end of 2006. Acta Oncologica. 2010;49(5):655-664.

5. Engeland A, Haldorsen T, Dickman PW, et al. Relative survival of cancer patients - a comparison between Denmark and the other Nordic countries. Acta Oncol. 1998;37(1):49-59.

6. The National Board of Health. Cancer Treatment Plans in Denmark [in Danish]. Available from: http://www.sst.dk/Udgivelser/2004. Accessed May 17, 2011.

7. Andersen TF, Madsen M, Jørgensen J, Mellemkjoer L, Olsen JH. The Danish National Hospital Register. A valuable source of data for modern health sciences. Dan Med Bull. 1999;46:263-268.

8. Pedersen CB, Gøtzsche H, Møller JO, Mortensen PB. The Danish Civil Registration System. A cohort of eight million persons. Dan Med Bull. 2006;53:441-449.

9. Brenner H, Rachet B. Hybrid analysis for up-to-date long-term survival rates in cancer registries with delayed recording of incident cases. Eur $J$ Cancer. 2004;40:2491-2501.

10. Tetsche MS, Nørgaard M, Skriver MV, Andersen ES, Lash TL, Sørensen HT. Accuracy of ovarian cancer ICD-10 diagnosis in a Danish population-based hospital discharge registry. Eur J Gyn Oncol. 2005;26:266-270.

11. Folkesson J, Engholm G, Ehrnrooth E, et al. Rectal cancer survival in the Nordic countries and Scotland. Int J Cancer. 2009;125:2406-2412.

12. Falebita OA, Mancini S, Kiely E, Comber H. Rising incidence of renal cell carcinoma in Ireland. Int Urol Nephrol. 2009;41(1):7-12.

13. Wunderlich H, Schumann S, Jantitzky V, et al. Increase of renal cell carcinoma incidence in central Europe. Eur Urol. 1998;33(6): 538-541.

14. Beisland C, Medby PC, Beisland HO. Renal cell carcinoma: gender difference in incidental detection and cancer-specifik survival. Scand J Urol Nephrol. 2002;36(6):414-418.

15. Gudbjartsson T, Thoroddsen A, Petursdottir V, Hardarson S, Magnusson J, Einarsson GV. Effect of incidental detection for survival of patients with renal cell carcinoma: results of population-based study of 701 patients. Urology. 2005;66(6):1186-1191.

16. Hudes G, Carducci M, Tomczak P, et al. Temsirolimus, interferon alfa, or both for advanced renal-cell carcinoma. N Engl J Med. 2007;356: 2271-2281.

17. Motzer RJ, Hutson TE, Tomczak P, et al. Overall survival and updated results for sunitinib compared with interferon alfa in patients with metastatic renal cell carcinoma. J Clin Oncol. 2009;27:3584-3590.

18. Escudier B, Pluzanska A, Koralewski P, et al. Bevacizumab plus interferon alfa-2a for treatment of metastatic renal cell carcinoma: a randomised, double-blind phase III trial. Lancet. 2007;370:2103-2111.
Clinical Epidemiology

\section{Publish your work in this journal}

Clinical Epidemiology is an international, peer-reviewed, open access journal focusing on disease and drug epidemiology, identification of risk factors and screening procedures to develop optimal preventative initiatives and programs. Specific topics include: diagnosis, prognosis, treatment, screening, prevention, risk factor modification, systematic

Submit your manuscript here: http://www.dovepress.com/clinical-epidemiology-journal

\section{Dovepress}

reviews, risk \& safety of medical interventions, epidemiology \& biostatical methods, evaluation of guidelines, translational medicine, health policies \& economic evaluations. The manuscript management system is completely online and includes a very quick and fair peer-review system, which is all easy to use. 